\title{
Identifying Effective Factors on Using Service Oriented Achitecture in E- Banking
}

\author{
Seyed Hossein Siadat \\ Assistant Professor, IT-Management Group, Department of Management and Accounting, ShahidBeheshti University, \\ Tehran, Iran \\ H_siadat@sbu.ac.ir \\ SajjadShokohyar \\ Assistant Professor, IT-Management Group, Department of Management and Accounting, ShahidBeheshti University, \\ Tehran, Iran \\ S_shokohyar@sbu.ac.ir \\ Sara Shafahi \\ M.Sc. in IT Management, Department of Management and Accounting, ShahidBeheshti University, Tehran, Iran
}

\begin{abstract}
One of the common problems of most banks in information technology in banking area is the lack of software integrity and data banks. For integrating goals, various methods and technologies have been developed. Service oriented architecture (SOA) is among the state of art technologies. The most important goal of employing SOA in e-banking includes enhancing the re-usage level and flexibility of information services, flexibility of information technology in response to continuous business changes, standardization and integration of systems and IT infrastructures. In spite of this, unluckily, most banks experience failure in employing this technology. According to the recent surveys, one of the bank's failure reasons, is the lack of a comprehensive framework which comprises all effective factors of this architecture. Thus, the goal of this paper is to detect and analyze the effective factors on service oriented architecture in e-banking and providing a comprehensive framework which encompass all factors. This conceptual framework is essential for banks in implementing SOA properly in e-banking area. In this research, first, in this research effective factors of using SOA was detected by a case study, then most repeated factors were classified. By using statistical software, e.g. SPSS, Excel, statistical tests, e.g. validity and reliability tests and descriptive statistical tests were conducted and the most important factors were detected and a prioritized. As a result of this prioritization, the integration factor of systems had the most and organization features had the least significant effect on using SOA in e-banking.
\end{abstract}

\section{Indexing terms/Keywords}

Information Systems; Service Oriented Architecture; E-banking; Effective Factors; Comprehensive Framework.

\section{Academic Discipline and Sub-Disciplines}

Information Technology

\section{SUBJECT CLASSIFICATION}

Web Based Information Systems, Service Oriented Architecture

\section{TYPE (METHOD/APPROACH)}

Analysis and Modeling; Survey/Questionnaire

\section{INTRODUCTION}

Nowadays organizations face with unstable competitive environment which is rapidly growing. These fluctuations are due to various factors, e.g. technological changes, shortening of product life-cycle and globalization od economy (Siadat, et al, 2014). In the past, each organization defined a distinctive system for each process that was called island system. These systems Lack of communication caused problems like heterogeneous and replicated data, lack of interaction among processes, etc. so, the idea of integrative systems was introduced (Atashak\&Mahzade, 2011). Since a business system contains various relevant sub-systems, designing and implementation of systems is a time consuming process. But if implementation of business processes would be done under services in the coverage of SOA, these problems can be overcome (Basias et al, 2015). Regarding the importance of SOA and organization tendencies and boosting information volume, this architecture acceptance has significant importance in banking systems. Integrating is important in the success of banking, especially e-banking and banks are required to integrate IT infrastructures for preparing proper ebanking services. SOA is an advanced integrating paradigm that can support banks in solving problems (Riad et al, 2008). In spite of this, many relevant issues regarding employing SOA in e-banking still remains unknown. For various reasons, including lack of a comprehensive framework which encompass different viewpoints, many banks experience failure in reaching the benefits of integration in e-banking. It is worth mentioning that limited background about effective factors on utilizing SOA in e-banking and lack of a comprehensive framework that explain these factors has created a major research issue that requires more studies and investigations (Alghatani, 2015). Nowadays banks improve their services continuously and develop safe electronic banking services via new channels (Lee et al, 2010). For this reason, they seek for efficient techniques in system integration and services. During the last decade they had the tendency to use SOA. 


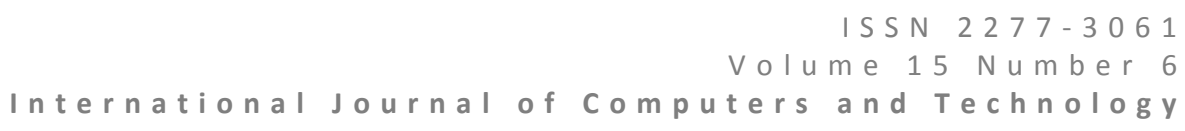

Therefore the goal of present paper is to detect and analyze effective factors on employing SOA in e-banking and prioritization among them for determining the most effective factor and providing a comprehensive framework of effective factors. In order to conduct this study, key issues like e-banking, organizational architecture and service based organization has been concentrated. For this purpose, The distinctive feature of present study in comparison to the past ones is in developing effective factors of SOA acceptance and adding new dimensions to SOA framework. It also helps banks in taking important decisions related to using this architecture, realizing benefits, risks, costs and relevant changes of using SOA in e-banking.

In the next section, research background will be referred and proposed framework will be introduced. Then type and research method and results of data analysis by using SPSS software and final framework and conclusion will be presented, respectively.

\section{RESEARCH BACKGROUNG}

Various definitions have been given regarding electronic banking, some of them include: concentration on new distribution channels, presenting customers with new modified services, and utilizing electronic commerce strategies (BahriNejad\&Khalaj, 2011) providing customers with banking services by using safe interfaces without physical presence (Allame\&Zare, 2011) customer usage of internet for organizing, experimenting or conducting changes in bank account or investing in banks and new and traditional banking services (MoshrefJavadi, 2012) to customers via electronic mutual communicational channels (Zeithmal, 2000).

Service oriented architecture is not a new concept and has developed since 90 s. What is new is the capability of realizing its successful implementation. SOA solution for integrating communicational systems is to connect informational systems via web-service. Since late of $90 \mathrm{~s}$, in order to challenge interactivity of informational systems, different approaches have been presented in which the most famous ones include peer to peer and central interface based integration (Riad et al , 2008). In peer to peer, data are needed for interaction between two systems which requires providing specific data path. Such an approach was too expensive and is hard to deal with and making changes was difficult. With the advent of SOA previous problems were solved and sectors were defined as services so as to be changeable easily. Major purposes of SOA include standardization and integrating platforms and technological infrastructures in an organization, improving inter-organization interactivity, reusing and flexibility of information services, more alignment of information technology with business (Lee et al, 2010).

Nowadays banks seek for efficient techniques for integrating systems and services. One promising solution for banks to communicate among IT solutions and solving integration plans related to e-banking is SOA (Uthria\&Rabhi, 2009). By employing this new technique and technology, customers can transfer their request via a standard coordinator on the web to bank. In this way, customer's data will be collected in a comprehensive data base (Siadat\&Hemati, 2014). limited background around effective factors of employing SOA in e-banking and lack of a comprehensive framework that explains them, has created a major research problem that requires more studies (Niknejad et al, 2014), thus, detecting and analyzing effective factors on employing SOA in e-banking is among the results of this study. According to the conducted surveys in past studies, factors can be divided in to 4 categories:

1. Business: It relates to factors playing role in decisions regarding employing SOA in e-banking. These factors include business alignment, communication, target, strategy, risk etc (Basia et al, 2012/ Lawler et al, 2008/ Themistocleius et al, 2014).

2. Technical: New solution in present IT infrastructure effects on technical factors related to support. Thus, IT infrastructure and general security of system must be carefully investigated (Basias et al, 2015/ Themistocleius et al,2014/ Lee et al,2010).

3. Human: It refers to the factors related to staff, including fatigue, skills, stress and resistance to change. These factors can effect staff behavioral instance to conduct a SOA solution in e-banking. Therefore, it effects decision making process (Basias et al,2012/ Luthria and Rabhi,2009/ Lawler et al, 2008).

4. Procedural: It focuses on factors that support banks in decision making regarding using SOA in e-banking and evaluating different issues like obstacles, benefits and expenses that effect on organizational performance (Themistocleius et al,2014/ Basias et al,2012/ Lee et al,2010).

As it was indicated, although researches have been conducted on SOA, a few studies have been conducted on effective factors of using SOA in e-banking. This issue has caused limitations, including: banks have problems dealing with integrating issues, While e-banking operations cover an important section of banking operations, and it will be developed in future. For this purpose, in this study, SOA frameworks and models were investigated for detecting effective factors of employing SOA in e-banking and a decision framework was prepared for using SOA in e-banking according to an extensive review. In order to categorize the effective factors, past research categories were used. Analyzing models and frameworks related to employing SOA indicates that the factors and their categories are not identical among researchers (Lawler et al, 2009). In order to conduct this study, 118 factors presented in recent studies among present backgrounds that were effective in using SOA in e-banking were detected. In depth analysis, factors were reduced to 24 in order to be investigated in a real banking environment. As it was indicated, according to past studies, these factors can be categorized in 4 groups that include; business, technical, human, procedural. They are illustrated in the following table.

1. Business Factors: It includes components in the domain of organizational management, e.g. strategy and target, level of awareness, and management support in employing SOA. other cases are listed in table 1. 
International Journal of Computers and Technology

Table 1. Possible Business factors effective in employing SOA

\begin{tabular}{|c|c|c|c|}
\hline z & $\begin{array}{l}\text { Possible influential } \\
\text { factors } \\
\text { of SOA adoption in } \\
\text { e-banking }\end{array}$ & Description & Reference \\
\hline 1 & Cost & $\begin{array}{l}\text { Direct and un direct human } \\
\text { costs }\end{array}$ & $\begin{array}{l}\text { Lawler et al(2008), Mohamad and Ismail(2009), } \\
\text { Schonewille\&Bouwman (2010), Themistocleous } \\
\text { et al (2014), Basias et al(2015) }\end{array}$ \\
\hline 2 & Strategy & $\begin{array}{l}\text { Long-term business } \\
\text { planning }\end{array}$ & $\begin{array}{l}\text { Lawler et al. (2008), Luthria and } \\
\text { Rabhi(2009),Schonewille and Bouwman(2010), } \\
\text { Basias et al(2012) \& (2013) \& (2015), } \\
\text { Themistocleous et al, (2014) }\end{array}$ \\
\hline 3 & Goal & $\begin{array}{l}\text { Clear targeting based on } \\
\text { business value related to } \\
\text { SOA adoption }\end{array}$ & $\begin{array}{l}\text { Lee et al. (2010) Lawler et al (2008),IBM (2008), } \\
\text { Basias et al (2012) \& (2013) \& (2015), } \\
\text { Themistocleous et al(2014) }\end{array}$ \\
\hline 4 & Return on Investment & $\begin{array}{l}\text { clear targeting based on } \\
\text { bussiness value related to } \\
\text { SOA adoption }\end{array}$ & $\begin{array}{l}\text { Lowler et al(2008), HP(2008), Luthria and Rabhi } \\
\text { (2009), Mohamad and Ismail (2009), Basias et al, } \\
(2012) \&(2013) \&(2014)\end{array}$ \\
\hline 5 & $\begin{array}{l}\text { IT and business } \\
\text { alignment }\end{array}$ & $\begin{array}{l}\text { Successful alignment of IT } \\
\text { with business, actors, } \\
\text { processes and technology }\end{array}$ & $\begin{array}{l}\text { Luthria and Rabhi (2009), IBM (2008), HP(2008), } \\
\text { Basias et al(2012) \& } \\
\text { (2013)\&(2015),Themistocleous et al (2014) }\end{array}$ \\
\hline 6 & Communications & $\begin{array}{l}\text { Good comminucation } \\
\text { among different } \\
\text { departments }\end{array}$ & $\begin{array}{l}\text { Lawler et al. (2008), Mohamad and Ismail } \\
\text { (2009), Schonewille\&Bouwman( 2010), Lee et } \\
\text { al(2010), Basias et al, (2012)\& (2013)\& (2015), } \\
\text { Themistocleous et al (2014) }\end{array}$ \\
\hline 7 & $\begin{array}{l}\text { Awareness and } \\
\text { support of } \\
\text { management }\end{array}$ & $\begin{array}{l}\text { Top Managers view on } \\
\text { service oriented } \\
\text { architecture }\end{array}$ & $\begin{array}{l}\text { IBM, (2008), Luthria and Rabhi (2009),Basias et } \\
\text { al (2012) Themistocleous et al (2014) }\end{array}$ \\
\hline 8 & Time & $\begin{array}{l}\text { Decrease of required time } \\
\text { for introduction of new } \\
\text { services to the market, and } \\
\text { Save time by reducing } \\
\text { downtime }\end{array}$ & $\begin{array}{l}\text { Lawler et al (2008), HP(2008), } \\
\text { Schonewille\&Bouwman (2010), Basias et al } \\
\text { (2012)\&(2014), IBM(2008), Mohamad and Ismail } \\
\text { (2009),Mohamad and Ismail (2009) }\end{array}$ \\
\hline
\end{tabular}

2. Technical Factors: This factor encompasses components related to the required technologies for employing SOA, e.g. IT infrastructure and other cases listed in table 2.

Table 2. Possible Technical factors effective in employing SOA

\begin{tabular}{|l|l|l|l|}
\hline 9 & $\begin{array}{l}\text { Standardization } \\
\text { Processes }\end{array}$ & $\begin{array}{l}\text { Business process need to } \\
\text { standardization }\end{array}$ & $\begin{array}{l}\text { Lawler et al (2008), IBM(2008), } \\
\text { HP(2008),Schonewille\&Bouwman (2010), Lee et } \\
\text { al(2010),Basias et al (2012) }\end{array}$ \\
\hline 10 & Compatibility & $\begin{array}{l}\text { Compatibility with existing } \\
\text { softwares and programes }\end{array}$ & $\begin{array}{l}\text { IBM (2008), Lawler et al (2008), } \\
\text { Schonewille\&Bouwman (2010) }\end{array}$ \\
\hline 11 & Complexity & architecher adoption difficulty & $\begin{array}{l}\text { HP(2008), Mohamad and Ismail (2009), Lee et al } \\
(2010)\end{array}$ \\
\hline 12 & IT infrastructure & $\begin{array}{l}\text { Hardware and software and } \\
\text { people related infrastructure }\end{array}$ & $\begin{array}{l}\text { Lawler et al(2008), IBM (2008), Mohamad and } \\
\text { Ismail (2009), Themistocleous et al( 2014),Basias } \\
\text { et al(2012)\&(2013)\&(2015) }\end{array}$ \\
\hline
\end{tabular}




\begin{tabular}{|c|c|c|c|}
\hline 13 & Security & $\begin{array}{l}\text { Data and Transactions } \\
\text { security in E-banking }\end{array}$ & $\begin{array}{l}\text { Lawler et al (2008), IBM (2008), Mohamad and } \\
\text { Ismail (2009), Lee et al( 2010), Basias et al(2013) } \\
\& \text { (2015), Themistocleous et al, (2014) }\end{array}$ \\
\hline 14 & Reusability & $\begin{array}{l}\text { limprovement of software } \\
\text { reuse and applications }\end{array}$ & Lawler et al, (2008), Basias et al, (2012)\& (2014) \\
\hline 15 & Systems integration & $\begin{array}{l}\text { Systems and applications } \\
\text { need to Integration }\end{array}$ & $\begin{array}{l}\text { HP(2008), Schonewille\&Bouwman (2010), Lee et } \\
\text { al(2010), Basias et al (2012)\& (2014) }\end{array}$ \\
\hline 16 & $\begin{array}{l}\text { Agility, efficiency } \\
\text { and flexibility of } \\
\text { processes }\end{array}$ & $\begin{array}{l}\text { Increase the agility, efficiency } \\
\text { and flexibility of business } \\
\text { processes }\end{array}$ & $\begin{array}{l}\text { Schonewille\&Bouwman (2010), Luthria and Rabhi } \\
\text { (2009), Basias et al, (2014) }\end{array}$ \\
\hline
\end{tabular}

3. Human Factors: this factor encompass components related to an organization staff . it also effects the staff and their working procedure, e.g. fatigue, stress and other things listed in table 3.

Table 3. Possible Human factors effective in employing SOA

\begin{tabular}{|c|c|l|l|}
\hline 17 & $\begin{array}{r}\text { Resistance to } \\
\text { Change }\end{array}$ & $\begin{array}{l}\text { Resistance to changes } \\
\text { related to new things }\end{array}$ & $\begin{array}{l}\text { IBM (2008), Lee et al (2010), Basias et al (2012) } \\
\&(2013) \&(2015), \text { Themistocleous et al (2014) }\end{array}$ \\
\hline 18 & Fatigue & $\begin{array}{l}\text { Fatigue by time, work } \\
\text { amount and training }\end{array}$ & $\begin{array}{l}\text { Luthria and Rabhi (2009), Mohamad and Ismail } \\
\text { (2009), Lee et al (2010), Themistocleous et } \\
\text { al(2014), Basias et al (2012) \&(2013) \& (2015) }\end{array}$ \\
\hline 19 & Stress & $\begin{array}{l}\text { Stresbyd time, work amount } \\
\text { and training }\end{array}$ & $\begin{array}{l}\text { Luthria and Rabhi (2009), Lee et al (2010),Basias } \\
\text { et al(2012) \& (2013) \&(2015), Themistocleous et } \\
\text { al(2014) }\end{array}$ \\
\hline 20 & Staff skills & $\begin{array}{l}\text { Personnel experience and } \\
\text { training, required IT } \\
\text { knowledge existence in } \\
\text { organization }\end{array}$ & $\begin{array}{l}\text { HP(2008), Mohamad and Ismail (2009), } \\
\text { Schonewille\&Bouwman (2010), Themistocleous et } \\
\text { al (2014), Basias et al (2012) \& (2014), Lawler et } \\
\text { al (2008), Luthria and Rabhi (2009),Basias et } \\
\text { al(2012) }\end{array}$ \\
\hline
\end{tabular}

4. Procedural factors: this factor encompasses components related to internal and external organizational environments, e.g. organization features, competitive environment in which organization is located and other cases listed in table 4.

Table 4. Possible procedural factors effective in employing SOA

\begin{tabular}{|l|l|l|l|}
\hline 21 & $\begin{array}{l}\text { Features } \\
\text { organization }\end{array}$ & $\begin{array}{l}\text { organization size and industry } \\
\text { type }\end{array}$ & $\begin{array}{l}\text { Mohamad and Ismail (2009), Luthria and Rabhi } \\
\text { (2009), Schonewille\&Bouwman (2010), Basias et } \\
\text { al(2012) }\end{array}$ \\
\hline 22 & $\begin{array}{l}\text { Change } \\
\text { management }\end{array}$ & Organizing developed changes & $\begin{array}{l}\text { Lawler et al, (2008), IBM(2008), Luthria and } \\
\text { Rabhi (2009), Schonewille\&Bouwman (2010), } \\
\text { Basias et al(2012) }\end{array}$ \\
\hline 23 & $\begin{array}{l}\text { Foreign } \\
\text { Pressures }\end{array}$ & $\begin{array}{l}\text { The existing pressure among } \\
\text { similar organizations in } \\
\text { competition atmosphere }\end{array}$ & $\begin{array}{l}\text { IBM (2008), Luthria and Rabhi } \\
\text { (2009),Schonewille\&Bouwman, } \\
(2010), \text { Themistocleous et al 2014 }\end{array}$ \\
\hline 24 & $\begin{array}{l}\text { Organizational } \\
\text { Culture }\end{array}$ & $\begin{array}{l}\text { Increasing collaboration culture } \\
\text { between it and business }\end{array}$ & $\begin{array}{l}\text { IBM(2008), Luthria and Rabhi(2009), Lee et al. } \\
\text { (2010), Schonewille and Bouwman(2010),Basias } \\
\text { et al(2012), Themistocleous et al (2014) }\end{array}$ \\
\hline
\end{tabular}

Based on factors above mentioned in tables, we presented our proposed framework (Figure 1). 


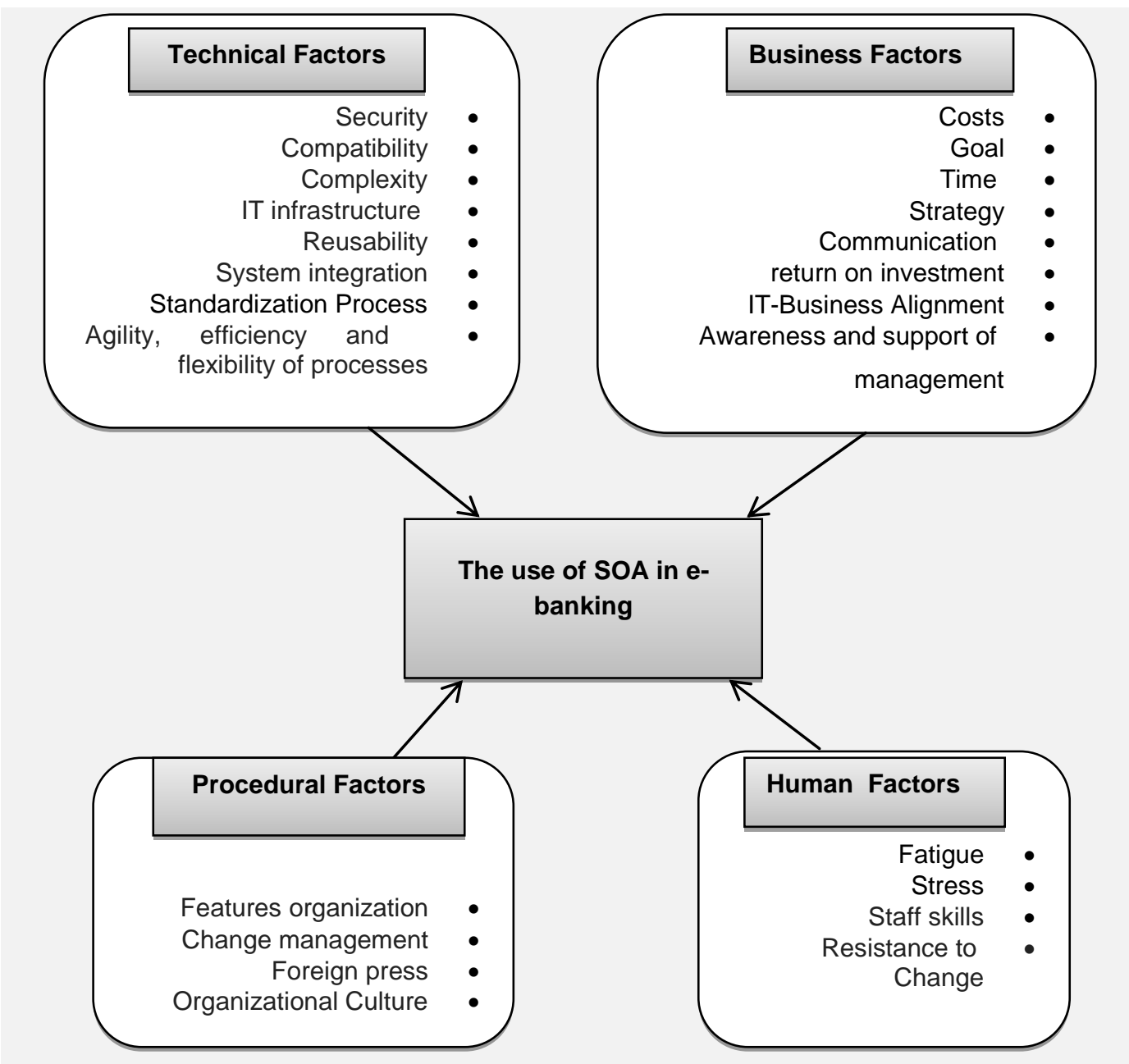

Fig 1: Proposed Framework

\section{RESEARCH METHOD}

This research is of applied form since it intends to develop a technology for applying in a specific field of banking. Research method is based on data gathering and it considers subject contents, present conditions of available phenomenon, and is of descriptive type. In order to measure the research variables, concepts were investigated by selecting a sample representative of statistic population and distributing questionnaire. In the next step the results were generalized to the whole population. Therefore the present study, is survey research regarding descriptive research categories (Sarmad et al, 1383). In this research a heuristic research model has been used. In order to gather operational data and measure variables, questionnaire and Likert scale have been used respectively. Experimental data extracted from a case study related to SOA in e-banking, have been prioritized and have been analyzed to get experimental results. The goal of prioritization in this qualitative research is to boost validity and reliability of finings. The proposed framework regarding effective factors on using SOA in e-banking has been tested via a case study in e-banking.

\section{Determination of Validity And Reliability of The Questionnaire}

First, in order to investigate the extent to which available sample questions represent the entire community of possible questions, we addressed the validity of data using SPSS software. Also, we conducted the reliability test to examine the correlation between questions of the questionnaire. If the correlation between scores of the tests measuring a single character is high, the questionnaire has convergent validity. The existence of this correlation is essential to ensure that the test will measure what is to be measured. For convergent validity, average variance extracted (AVE) and composite reliability $(\mathrm{CR})$ are calculated. For this purpose, the following relationship should be established between them:

\section{$\mathrm{CR}>0.7 \& \mathrm{CR}>\mathrm{AVG} \& \mathrm{AVG}>0.5$}

Table 5. Convergent validity and reliability of variables

\begin{tabular}{|c|c|c|c|r|}
\hline CR & AVE & Cronbach's alpha & Numbers of questions & \\
\hline 0.827 & 0.558 & 0.728 & 17 & Business Factors \\
\hline 0.905 & 0.761 & 0.843 & 16 & Technical Factors \\
\hline
\end{tabular}




\begin{tabular}{|l|l|l|l|r|}
0.807 & 0.731 & 0.761 & 8 & Human Factors \\
\hline 0.792 & 0.582 & 0.765 & 8 & FactorsProcedural \\
\hline 0.703 & 0.672 & 0.735 & 8 & SOA \\
\hline
\end{tabular}

To investigate the reliability of data, Cronbach's alpha coefficient is used which is one of the most commonly used methods of measuring reliability of questionnaires and determines how well questions correlate with each other. Obviously, the more Cronbach's alpha index is close to 1 , the more questions are internally correlated and therefore homogeneous. Cronbach considers reliability coefficient of $45 \%$ low and coefficient of $75 \%$ moderate and acceptable. In this research, as shown in Table 5, Cronbach's alpha coefficients of all variables are more than 0.7 and therefore all variables are approved in terms of reliability. Average variance extracted (AVE) is always more than 0.5 , so convergent validity is also confirmed. Moreover, composite reliability $(\mathrm{CR})$ is larger than AVE in all factors, so all conditions of convergent validity are satisfied and the sample questions appropriately represent the population.

\section{DATA ANALYSIS}

\section{Descriptive Analysis of Research Variables}

To conduct this research, we used 2 questionnaires to assess independent and dependent variables. The statistical population consists of 80 employees of a private bank in Iran among which 70 people have been randomly selected as the sample. Descriptive analysis of dependent variables of the research has been presented in Table 6 based on central parameters (mean, median, and mode) and dispersion parameters (standard deviation, variance, and range).

Table 6. Descriptive analysis of dependent variables

\begin{tabular}{|c|c|c|c|c|c|c|c|c|c|}
\hline $\begin{array}{l}3 \\
\frac{3}{0} \\
\frac{x}{3} \\
\frac{1}{3} \\
0\end{array}$ & $\begin{array}{l}3 \\
\overline{3} . \\
\overline{3} \\
\frac{5}{3}\end{array}$ & 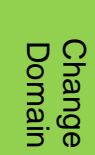 & 㐫. & 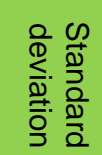 & $\frac{3}{\circ}$ & 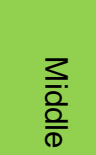 & $\begin{array}{l}\stackrel{D}{<} \\
\frac{D}{D N} \\
\frac{0}{D}\end{array}$ & $\begin{array}{l}\text { ᄋ } \\
\text { ㄷ } \\
\text { ㄹ }\end{array}$ & \\
\hline 4.438 & 3.250 & 1.188 & 0.069 & 0.263 & 3.750 & 3.813 & 3.821 & 70 & Technical Factors \\
\hline 4.625 & 3.000 & 1.625 & 0.125 & 0.354 & 4.000 & 3.750 & 3.739 & 70 & Human Factors \\
\hline 4.300 & 3.000 & 1.300 & 0.068 & 0.261 & 3.650 & 3.600 & 3.589 & 70 & Business Factors \\
\hline 4.125 & 2.625 & 1.500 & 0.149 & 0.386 & 3.375 & 3.250 & 3.252 & 70 & Procedural Factors \\
\hline
\end{tabular}

Descriptive analysis of dependent variables of the research has been presented in Table 7 based on central parameters (mean, median, and mode) and dispersion parameters (standard deviation, variance, and range).

Table 7. Descriptive analysis of independent variables

\begin{tabular}{|c|c|c|c|c|c|c|c|c|c|}
\hline $\begin{array}{l}\frac{3}{3} \\
\frac{0}{x} \\
\overline{3} \\
\frac{2}{3} \\
3\end{array}$ & 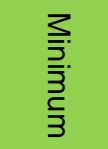 & 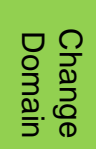 & 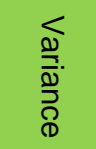 & 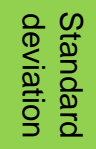 & $\frac{3}{\circ}$ & $\frac{\grave{c}}{\frac{3}{1}}$ & 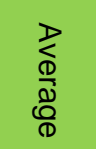 & $\stackrel{\text { O }}{\stackrel{2}{c}}$ & \\
\hline 5.000 & 3.000 & 3.000 & 0.320 & 0.566 & 5.000 & 4.500 & 4.478 & 70 & System integration \\
\hline 5.000 & 3.000 & 2.000 & 0.390 & 0.625 & 4.000 & 4.000 & 4.242 & 70 & Standardization Process \\
\hline 5.000 & 3.000 & 2.000 & 0.448 & 0.670 & 4.000 & 4.000 & 4.185 & 70 & IT infrastructure \\
\hline 5.000 & 3.000 & 2.000 & 0.454 & 0.674 & 4.000 & 4.000 & 4.178 & 70 & $\begin{array}{c}\text { Agility, efficiency and flexibility of } \\
\text { processes }\end{array}$ \\
\hline 5.000 & 2.000 & 3.000 & 0.458 & 0.677 & 4.000 & 4.000 & 3.950 & 70 & Staff skills \\
\hline 5.000 & 2.000 & 3.000 & 0.633 & 0.796 & 4.000 & 4.000 & 3.925 & 70 & IT-Business Alignment \\
\hline 5.000 & 2.000 & 3.000 & 0.473 & 0.688 & 4.000 & 4.000 & 3.885 & 70 & Resistance to Change \\
\hline 4.000 & 2.000 & 2.000 & 0.522 & 0.723 & 4.000 & 4.000 & 3.792 & 70 & Organizational Culture \\
\hline
\end{tabular}




\begin{tabular}{|c|c|c|c|c|r|r|r|r|c|}
5.000 & 2.000 & 3.000 & 0.473 & 0.688 & 4.000 & 4.000 & 3.750 & 70 & Change management \\
\hline 5.000 & 2.000 & 3.000 & 0.531 & 0.729 & 4.000 & 4.000 & 3.735 & 70 & $\begin{array}{c}\text { Awareness and support of } \\
\text { management }\end{array}$ \\
\hline 5.000 & 2.000 & 3.000 & 0.523 & 0.730 & 4.000 & 4.000 & 3.714 & 70 & return on investment \\
\hline 5.000 & 2.000 & 3.000 & 0.466 & 0.683 & 4.000 & 4.000 & 3.692 & 70 & Strategy \\
\hline 5.000 & 2.000 & 3.000 & 0.707 & 0.841 & 4.000 & 4.000 & 3.678 & 70 & Communication \\
\hline 4.000 & 2.000 & 2.000 & 0.432 & 0.658 & 3.500 & 3.500 & 3.632 & 70 & Security \\
\hline 5.000 & 2.000 & 3.000 & 0.379 & 0.616 & 4.000 & 4.000 & 3.614 & 70 & Goal \\
\hline 5.000 & 2.000 & 3.000 & 0.562 & 0.750 & 4.000 & 4.000 & 3.600 & 70 & Time \\
\hline 4.000 & 2.000 & 2.000 & 0.454 & 0.674 & 4.000 & 4.000 & 3.585 & 70 & Fatigue \\
\hline 5.000 & 2.000 & 3.000 & 0.401 & 0.634 & 4.000 & 4.000 & 3.568 & 70 & Reusability \\
\hline 4.000 & 2.000 & 2.000 & 0.480 & 0.693 & 3.000 & 3.500 & 3.535 & 70 & Compatibility \\
\hline 4.000 & 1.000 & 3.000 & 0.319 & 0.565 & 3.500 & 3.500 & 3.535 & 70 & Stress \\
\hline 4.000 & 2.000 & 2.000 & 0.544 & 0.738 & 3.000 & 3.000 & 2.771 & 70 & Foreign press \\
\hline 4.000 & 1.000 & 3.000 & 0.471 & 0.685 & 3.000 & 3.000 & 2.738 & 70 & costs \\
\hline 4.000 & 1.000 & 3.000 & 0.638 & 0.799 & 3.000 & 3.000 & 2.723 & 70 & Complexity \\
\hline 3.000 & 1.000 & 2.000 & 0.515 & 0.718 & 3.000 & 3.000 & 2.692 & 70 & Features organization \\
\hline
\end{tabular}

According to this table, it is clear that 70 correct responses to all questions of the research have been collected. These tables were set in descending order from the most effective to the least effective factors. Also, among dependent variables, the highest average belongs to technical factors with the amount of 3.821 which is higher than the average of Likert scale. The range fluctuates between 1 and 4. The minimum amount 3.252, is related to procedural factors. Procedural factors own the highest standard deviation. Median and mode show that most respondents chose options 3 and 4 which mean average and high. In the table related to independent variables, 70 correct responses to all questions of the research have been collected. Furthermore, among independent variables, the greatest average belongs to system integration factor with the amount of 4.478 which is even higher than the large amount of Likert scale. The lowest amount is for characteristics of the organization 2.692, being lower than the average amount of Likert scale.

\section{Final Conceptual Framework of The Research}

In this section, given the analyses of the data from questionnaires conducted using SPSS, the variables identified were prioritized and final research model has been presented. Based on average of responses to dependent variables, technical factors possessed the highest percentage following by business factors, human factors, and procedural factors. Among independent variables, system integration factor accounts for the highest percentage and the average of responses to the factors cost, complexity, external pressures, and organization features are less than the average of Likert scale and should be removed from the ultimate model.

According to an interview with and a survey of experts in the case of removal of two factors from procedural factors, it would be better if the two factors organizational culture and change management, which were among procedural factors and the average of the responses related to them was higher than the average of Likert, were maintained in the model. In this regard, it was found out that because these two factors are dependent upon organizational management, it is better to consider them under the umbrella of management in the organization and therefore they can be a subset of the business factor. The final research model is shown in Figure 2.

Considering the findings, in order to use service-oriented architecture in e-banking, it is first necessary to examine the affecting as well as inhibiting factors and then to make the plans needed to remove them. According to the analyses performed in the present study, owners and managers of a business, first, need to identify and provide the technology required for using this architecture in their own organization. Then, they have to investigate the factors affecting their business and its process so that the inhibiting factors can be identified. Finally, before implementing this architecture, they should provide personnel with their requirements and direct organizational culture towards the use of SOA in order not to face employee resistance and not to suffer from fatigue and stress while working. 


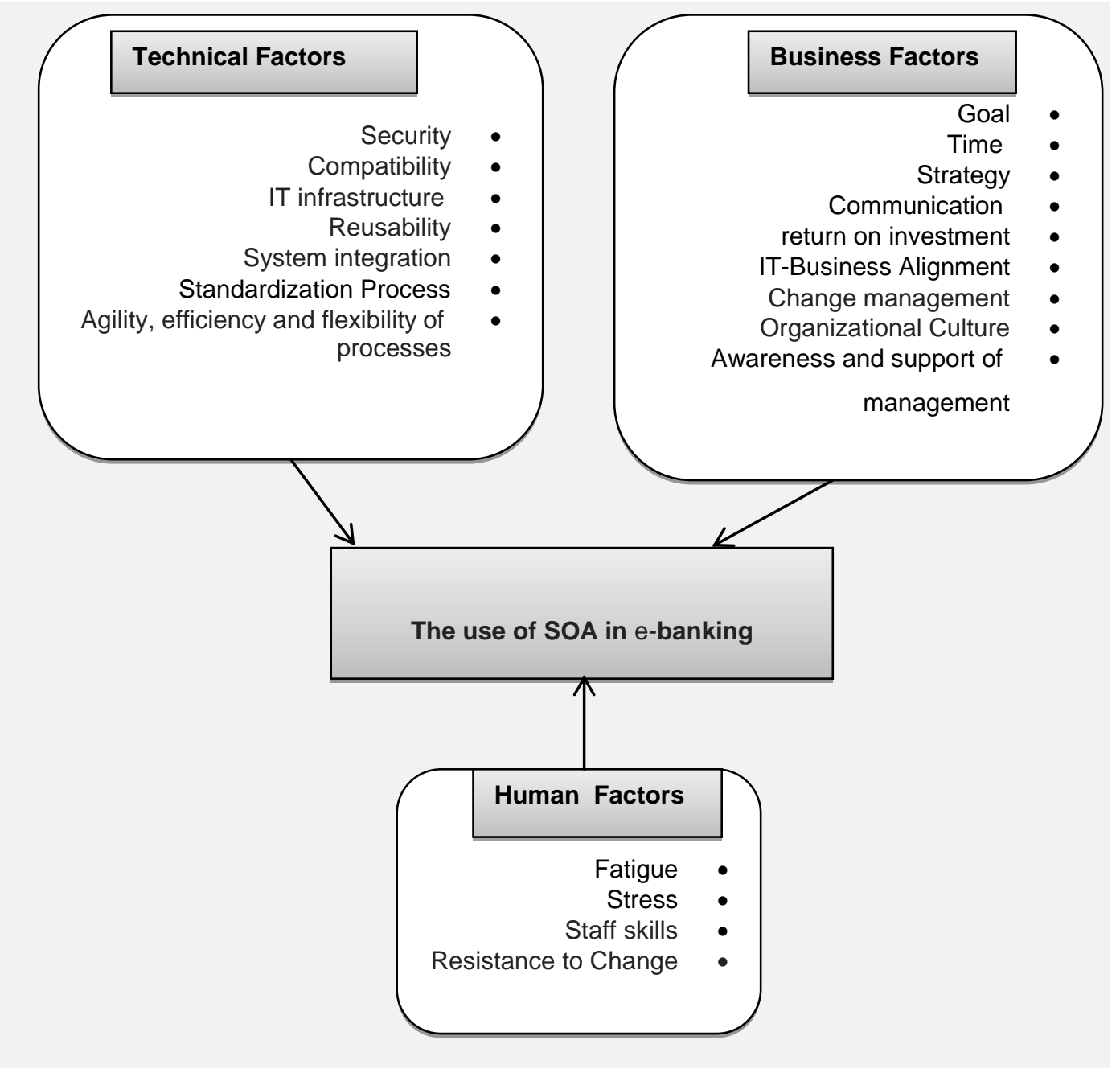

Fig 2: Final Framework

\section{CONCLUSIONS}

In this article, we investigated the need to integrate in e-banking and the role of service-oriented architecture in this integration. Banks are in search of the effects of SOA in e-banking and a comprehensive framework for the factors affecting its use will help us understand the benefits of SOA in e-banking. Without doubt, creating a comprehensive banking system and organizing the information are among the key elements to help banks with risk management, fighting with money laundering, quality control, creating an integrated marketing system, and other administrative issues (Siadat et al., 2015). The present literature shows that limited research has been done in this area. Lack of complete studies on the analysis of the factors influencing the use of SOA in e-banking led to lack of a comprehensive framework. This lack of a comprehensive framework does not allow organizations to gain full advantages of using SOA in e-banking and this is important. For this reason, we studied levels of e-banking and the use of SOA by focusing on identification of effective factors. Based on literature review findings, we recognized 118 effective factors and evaluated them, coming to the conclusion that all 118 factors are not unique. As a result, we proposed a conceptual framework based on 24 factors with the highest importance including: cost, strategy, target, return on investment, IT and business alignment, communications, awareness and support of management, time, process standardization, complexity, IT infrastructure, security, reusability, system integration, agility, efficiency, and flexibility of processes, resistance to change, fatigue, stress, and skills of employees. Each identified factor plays an important role during the use of SOA in e-banking. These factors are crucial for successful use of SOA and do not have the same value. The framework presented in practical area has been tested through a case study. The proposed conceptual framework provides new insights regarding identification and classification of the factors affecting the use of SOA in e-banking. The previous analysis suggests that there are several factors and classifications of factors related to the use of SOA. Hence, researchers do not share the same views. We clarified a lot of confusion in this area and proposed a framework that helps identify and clarify the factors influencing the use of SOA in ebanking. The case organization is a private bank and after a survey of its personnel regarding the use of SOA we came to the conclusion that dependent factors in terms of priority include: technical, business, human, and procedural factors, technical factors having the greatest effect. Also, independent factors in terms of priority include: system integration, process standardization, IT infrastructure, agility, efficiency, and flexibility of processes, employee skills, IT and business alignment, resistance to change, organizational culture, change management, awareness and support of senior management, return on investment, strategy, communications, security, target, time, fatigue, reusability, adaptability, 


\section{ISSN $2277-3061$ Volume 15 N u m ber 6 International Journal of Computers and Technology}

stress, external pressures, cost, complexity, organization features. The independent factors cost, complexity, external pressures, and organization features have the least effect so that they can be removed from the proposed model, resulting in 20 factors remained among which system integration factor is the most important one. We believe that the proposed framework will help banks when deciding on the use of SOA. The proposed framework can be employed as a strategic tool that gives competitive advantages to banks and may allow them to move faster and use integration solutions in a successful way that increases the realization of their interests. Considering the importance of e-banking and SOA, the proposed framework is expected to have important theoretical and practical implications.

\section{REFERENCES}

1. Zeithaml, A. 2000. Service Quality, Profitability and the Economic Worth of Customers: What We Know and What We Need to Learn. Journal of the Academy of Marketing Science. Volume 28, No. 1.

2. Lawler, J.P., et al. 2009 .Critical success factors in the planning of a service-oriented architecture (SOA) strategy for educators and managers. Information Systems Education Journal. 7(94).

3. Basias, N., Themistocleous, M., Morabito, V. 2013. SOA adoption in e-banking. Journal of Enterprise Information Management. 26(6).

4. Basias, N., Themistocleous, M., Morabito, V. 2015. A Decisio Making Framework for SOA Adoption in eBanking: A Case Study Approach. Journal of Economics, Business and Management, Vol. 3, No 1.

5. Siadat, S. H., \&Hemati, R. 2014. Improving Business Processes by Best Practices: A Case Study of Bank Commercial Civil Partnership Process.Management and Administrative Sciences Review, 3(5), 683-699.

6. Uthria, H., F. Rabhi. 2009. Service oriented computing in practice: an agenda for research into the factors influencing the organizational adoption of service oriented architectures. Journal of theoretical and applied electronic commerce research. 4(1), 39-56.

7. Lee, J.H., Shim, H., Kim, K. 2010. Critical success factors in SOA implementation: an exploratory study. Information Systems Management. 27(2), 123-145.

8. Siadat, S. H., Mohammadi, F., \&Ghazvinian, M. 2014. Innovation Effects on Customer Trust: The Case of Pasargad Bank. Management and Administrative Sciences Review, 3(6), 900-908.

9. Basias, N., Themistocleous, M., Morabito,V. 2012. Influential Factors of SOA Adoption in E-Banking. European Mediterenean\& Middle Eastern Conference on Information Systems.

10. Themistocleous, M., Basias, N., Morabito, V. 2014. A Framework for Service-Oriented Architecture Adoption in e-Banking: the case of banks from a Transition and a Developed Economy. Information Technology for Development.

11. Hu, C. 2011. Main Factors Affecting the Adoption and Diffusion of Web Service Technology Standards. in Computing and Intelligent Systems, 81-87.

12. Riad, M., Hassan, A., Hassan, Q. 2008. Leveraging SOA in Banking Systems Integration. Journal of Applied Economic Sciences. VolumellI_Issue2(4).

13. Siadat, S. H, Surani, A., Seyf, Sawideh.,Mohaghegh, R. 2015. Evaluating a Model for Implementing Knowledge Management in Banking Informatics Corporations in Iran, Journal: INTERNATIONAL JOURNAL OF COMPUTERS \& TECHNOLOGY. Vol 14 . No 4., 5599- 5606.

14. Niknejad, N., Ghani, I., CheHussin, A. 2014. Organization Factors Affected By SOA Adobtion: A Critical Overview. JOutnal of Theoretical and Applied Information Technology. Vol 64, No 2.

15. Alghatani, A. 2015. A Literature Review of the Factors Affecting Service Oriented Architecture Adoption in EBanking. International Journal of Engineering and Innovative Technology (IJEIT). Vol 5. Issue 3. 


\section{Author' biography with Photo}

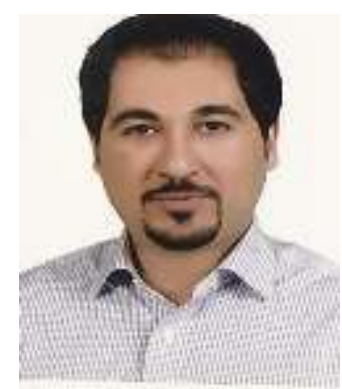

Seyed Hossein Siadat is working as an assistant professor at the department of Management and Accounting in ShahidBeheshti University (SBU) in Iran since January 2013. Previously he was a research scientist at the School of Technology Management at Ulsan National Institute of Science and Technology in South Korea. He received his $\mathrm{PhD}$ in Information Technology from Politecnico di Milano in Italy. He holds a M.Sc. in Information Technology - Management from University Technology Malaysia and B.Sc. in Software Engineering from Amirkabir University of Technology (AUT) in Iran. He has published about 60 papers on journals and main international conferences on information systems such as ICSOC, ICWS and CAiSE. His research interests include Service Oriented Computing, Quality of Service, Business Process Management, Business Process Reengineering, Process Mining, Soft Computing and organizational issues. 